\title{
Research on the supply chain model based on the differentiation of green agricultural products
}

\author{
Su Hui ${ }^{1}$, Cui Yuquan ${ }^{2, a}$ and Liu Bingjie ${ }^{3}$ \\ ${ }^{1}$ The School of mathematics, Shandong University, Jinan, 250100, China
}

\begin{abstract}
This paper studies the supply chain of green agricultural products with "agricultural super docking" mode based on the different management. The "agricultural super docking" mode is a direct connection between supermarkets and farmers (or cooperatives), what the supermarket needs and what the farmers produce. The green degree is used to indicate the quality level of health, safety and nutrition of agricultural products. The greater the green degree is, the better the quality of agricultural products is. In order to meet the needs of all consumers, the supermarket decide to carry out different management.That is to say,supermarket sells ordinary agricultural products and green agricultural products at the same time.This paper gives the consumer utility function for ordinary agricultural products and green agricultural products separately. We analyze the consumers' choice behaviors based on the consumer utility function .We discuss the optimal decision of supermarket choosing one farmer and supermarket choosing two farmers based on Stackelberg game. It can be seen from the comparison that supermarket can get more profits when it chooses two farmer to order separately. Finally, a "wholesale price + ordering subsidy" coordination mechanism is proposed to realize supply chain coordination. .
\end{abstract}

\section{Introduction}

With the development of agricultural modernization, the trading mode of agricultural products is also improving. "Agricultural super docking" is the direct docking of supermarkets with farmers (or cooperatives), what the supermarkets needs and what farmers produce directly. Reardon et allfound that the supply and marketing model of "agricultural super docking" was widely used in the central part of the Americas, some countries in Asia and the east of Europe. Thomas Reardon 2obtained that traditional farmers' markets will be gradually replaced by supermarkets, small agricultural producers and business operators will gradually eliminated by the market with the mode of operation of agricultural products supermarkets.Jiang zengwei 3 thought that the "agricultural super docking " is of great significance to improve the quality of agricultural products, the circulation of agricultural products and the increase of farmers' income. $\mathrm{Hu}$ Ding-nang, etc.4thought that "agricultural super docking " can promote the process of agricultural modernization in our country.

There are many literatures on the green degree in the study of supply chain of agricultural product. Li et al. 5obtained optimal price and green degree in the case of concentration and decentralization based on the Stackelberg game model. Liu et al.6studied the influence of consumers' green preference and horizontal competition degree on the operation of green supply chain. Fu li fang 7 study the factors that influences

\footnotetext{
${ }^{\mathrm{a}}$ Corresponding author: cuiyq@sdu.edu.cn
}

costomers to buy green products based on Probit regression forecasting model.

This paper studies the supply chain of "agricultural super docking" mode based on the differentiation of green agricultural products.

\section{Model construction}

Nowadays, green agricultural products are becoming more and more popular. Compared with ordinary agricultural products, green agricultural products are of high quality.But green agricultural production cost will be much higher than ordinary agricultural products.In terms of health and safety nutrition, consumers will tend to buy green agricultural products, but the sale prices of green agricultural products are much higher compared to ordinary agricultural products, and it is now the biggest factor that hinder the consumers to buy the green agricultural products. In this paper, we use the green degree to indicate the quality level of agricultural products. The higher the green degree of agricultural products is, the better the quality is.

Consumers' preference for green agricultural products varies depending on consumers' perceptions of green agricultural products, as well as economic conditions, knowledge levels, age, gender and so on. In order to meet the needs of most customers, retain more customers, the supermarket carries out different management . In other words, supermarket sales ordinary agricultural products and green agricultural products at the same time. It is assumed that ordinary 
agricultural products and green agricultural products have their respective green ranges. When $g<g_{0}$, it is ordinary agricultural products, and when $g \geq g_{0}$, it is agricultural products. It assume that consumers can only choose one of the ordinary agricultural products and green agricultural products . Consumers will estimate of the value of the agricultural products when they buy agricultural products. This paper constructs a consumer utility function , and consumers choose to purchase ordinary agricultural products or green agricultural products or give up purchasing the agricultural products based on the utility function.We assume that the consumer utility function is related to the green degree of agricultural products and prices. The consumer utility function can be assumed to be the multiplication of green and price: $u(g, p)=\theta m(g) \cdot n(p)$, It also can be assumed to be the additive form of green and price: $u(g, p)=\theta m(g)-n(p)$. In this paper,we assume consumer utility function as the additive form : $u(g, p)=\theta m(g)-n(p)$. Among them, $m(g)$ is the consumer utility of green degree of agricultural products, and $n(p)$ is the consumer utility of the price of agricultural products, and $\theta$ is the degree of consumer's green preference. We assume that $\theta$ is a random variable, obeying the uniform distribution on $[0, t]$. Learn from real life, when $g$ increases, $m(g)$ alse increases. In addition, when $g$ is relatively small, $\frac{d^{2} m(g)}{d g^{2}}>0$, But when $g$ gets to a certain value, it's going to be, $\frac{d^{2} m(g)}{d g^{2}}<0$. The general trend of the consumer utility function of the green degree of agricultural products can be expressed as figure 1 :

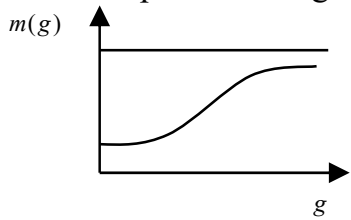

Figure 1

According to the above figure 1, the consumer utility of the green degree of agricultural products is roughly an s curve, which conforms to the logistic model. Therefore, we assume $\mathrm{m}(\mathrm{g})$ is subject to the logistic model. Namely, $m(g)=k /\left(1+a e^{-b g}\right)$ 。For simplicity ,we assume that $n(p)=p$.So the consumer utility function is: $u(g, p)=\theta k /\left(1+a e^{-b g}\right)-p$ 。

In this paper,we study the supply chain on

" Agricultural super docking " mode, the farmers direct docking with the supermarket, the supermarket need what and how much, farmers produce what and how much. The cost of producing ordinary produce and green produce is respectively $c_{f 1}, c_{f 2}$, and $c_{f 1}<c_{f 2}$. The wholesale price of ordinary agricultural products and green agricultural products are respectively $w_{f 1}$ 、 $w_{f 2}$. Before the start of business activities, supermarket signs a contract with farmers.Farmers decide the unit wholesale price, and supermarket decide unit sale price.The supermarket will give farmers compensation $c_{s} g$ for each unit of agricultural products, which can improve the green degree of agricultural products.

Consumer utility function of ordinary and green agricultural products are respectively:

$\left\{\begin{array}{l}u_{1}=\theta \frac{k}{1+a e^{-b g_{1}}}-p_{1} \\ u_{2}=\theta \frac{k}{1+a e^{-b g_{2}}}-p_{2}\end{array}\right.$

To discuss convenience, we let, $G_{1}=\frac{k}{1+a e^{-b g_{1}}}, \quad G_{2}=\frac{k}{1+a e^{-b g_{2}}}$

$\mu_{1}$ and $\mu_{2}$ are the consumer utility function of ordinary and green agricultural products respectively. The turning point of the consumer utility of the green degree of agricultural products is $g^{\prime}=-\frac{1}{b} \ln \frac{1}{a}$.According to the real life , $g^{\prime}>g_{0}$.

The necessary and sufficient condition for farmers to choose ordinary agricultural products is:

$$
\left\{\begin{array}{l}
u_{1} \geq 0 \\
u_{1} \geq u_{2}
\end{array}\right.
$$

From equation (2),we have :

$\left\{\begin{array}{l}\theta \geq \frac{p_{1}}{G_{1}} \\ \theta \leq \frac{p_{2}-p_{1}}{G_{2}-G_{1}}\end{array}\right.$,in order to make the study meaningful, it should be :

$\frac{p_{1}}{G_{1}} \leq \frac{p_{2}-p_{1}}{G_{2}-G_{1}}$, That is $p_{1} G_{2}-p_{2} G_{1} \leq 0$.

Under the condition of $p_{1} G_{2}-p_{2} G_{1} \leq 0$,

When $\theta \in\left[\frac{p_{1}}{G_{1}}, \frac{p_{2}-p_{1}}{G_{2}-G_{1}}\right]$, consumers will choose to buy ordinary agricultural products.

The necessary and sufficient condition for farmers to choose green agricultural products is:

$$
\left\{\begin{array}{l}
u_{2} \geq 0 \\
u_{2} \geq u_{1}
\end{array}\right.
$$

From equation (3), we have, $\left\{\begin{array}{l}\theta \geq \frac{p_{2}}{G_{2}} \\ \theta \geq \frac{p_{2}-p_{1}}{G_{2}-G_{1}}\end{array}\right.$

When $p_{1} G_{2}-p_{2} G_{1} \leq 0$, we have $\frac{p_{2}-p_{1}}{G_{2}-G_{1}} \geq \frac{p_{2}}{G_{2}}$ In order to make the study meaningful, it should be 
$\frac{p_{2}-p_{1}}{G_{2}-G_{1}} \leq t$, namely $p_{2}-p_{1}-t\left(G_{2}-G_{1}\right) \leq 0$.Under the condition

$\left\{\begin{array}{l}p_{1} G_{2}-p_{2} G_{1} \leq 0 \\ p_{2}-p_{1}-t\left(G_{2}-G_{1}\right) \leq 0\end{array}\right.$,When $\theta \in\left[\frac{p_{2}-p_{1}}{G_{2}-G_{1}}, t\right]$,consum ers will choose to buy green agricultural products .

To sum up, under the premise of this condition $\left\{\begin{array}{l}p_{1} G_{2}-p_{2} G_{1} \leq 0 \\ p_{2}-p_{1}-t\left(G_{2}-G_{1}\right) \leq 0\end{array}\right.$,

(1) When $\theta \in\left[0, \frac{p_{1}}{G_{1}}\right]$, consumers give up buying this agricultural products.

(2) When $\theta \in\left[\frac{p_{1}}{G_{1}}, \frac{p_{2}-p_{1}}{G_{2}-G_{1}}\right]$, consumers choose to buy ordinary agricultural products.;

(3) When $\theta \in\left[\frac{p_{2}-p_{1}}{G_{2}-G_{1}}, t\right]$, consumers choose to buy green agricultural products.

So the demand for ordinary produce is.

$Q_{1}=\left\{\begin{array}{l}\frac{p_{2} G_{1}-p_{1} G_{2}}{t G_{1}\left(G_{2}-G_{1}\right)}, p_{1} G_{2}-p_{2} G_{1} \leq 0 \\ 0, \text { others }\end{array}\right.$

The demand for green agricultural products is: $Q_{2}=\left\{\begin{array}{l}\frac{t\left(G_{2}-G_{1}\right)-p_{2}+p_{1}}{t\left(G_{2}-G_{1}\right)}, p_{1} G_{2}-p_{2} G_{1} \leq 0 \text { and } p_{2}-p_{1}-t\left(G_{2}-G_{1}\right) \leq 0 \\ 0, \text { others }\end{array}\right.$

Therefore, when $\left\{\begin{array}{l}p_{1} G_{2}-p_{2} G_{1} \leq 0 \\ p_{2}-p_{1}-t\left(G_{2}-G_{1}\right) \leq 0\end{array}, \quad\right.$ the revenue function of farmer is:

$$
\begin{aligned}
\pi_{f}= & \left(w_{f 1}-c_{f 1}+c_{s} g_{1}\right) \frac{p_{2} G_{1}-p_{1} G_{2}}{t G_{1}\left(G_{2}-G_{1}\right)} \\
& +\left(w_{f 2}-c_{f 2}+c_{s} g_{2}\right) \frac{t\left(G_{2}-G_{1}\right)-p_{2}+p_{1}}{t\left(G_{2}-G_{1}\right)}
\end{aligned}
$$

The revenue function of the supermarket is:

$$
\begin{aligned}
\pi_{s}\left(p_{1}, p_{2}\right)= & \left(p_{1}-w_{f 1}-c_{s} g_{1}\right) \frac{p_{2} G_{1}-p_{1} G_{2}}{t G_{1}\left(G_{2}-G_{1}\right)} \\
& +\left(p_{2}-w_{f 2}-c_{s} g_{2}\right) \frac{t\left(G_{2}-G_{1}\right)-p_{2}+p_{1}}{t\left(G_{2}-G_{1}\right)}
\end{aligned}
$$

The revenue function of the whole supply chain is:

$$
\begin{aligned}
\pi_{s c}\left(p_{1}, p_{2}\right) & =\left(p_{1}-c_{f 1}\right) \frac{G_{1} p_{2}-G_{2} p_{1}}{t G_{1}\left(G_{2}-G_{1}\right)} \\
& +\left(p_{2}-c_{f 2}\right) \frac{t\left(G_{2}-G_{1}\right)-p_{2}+p_{1}}{t\left(G_{2}-G_{1}\right)}
\end{aligned}
$$

\section{Centralized decision model}

If the supermarket want to carry out different management, it needs to be satisfied $\left\{\begin{array}{l}p_{1} G_{2}-p_{2} G_{1} \leq 0 \\ p_{2}-p_{1}-t\left(G_{2}-G_{1}\right) \leq 0\end{array} \quad\right.$.Therefore, optimization problem of the whole supply chain is a planning model:

$$
\begin{aligned}
\pi_{s c} & \left(p_{1}, p_{2}\right)=\left(p_{1}-c_{f 1}\right) \frac{G_{1} p_{2}-G_{2} p_{1}}{t G_{1}\left(G_{2}-G_{1}\right)}+\left(p_{2}-c_{f 2}\right) \frac{1}{t}\left(t-\frac{p_{2}-p_{1}}{G_{2}-G_{1}}\right) \\
\text { s.t. } & p_{1} G_{2}-p_{2} G_{1} \leq 0 \\
& p_{2}-p_{1}-t\left(G_{2}-G_{1}\right) \leq 0
\end{aligned}
$$

To solve the model (7),we have :

Property 1. when $\left\{\begin{array}{c}G_{2} c_{f 1}-G_{1} c_{f 2} \leq 0 \\ c_{f 2}-c_{f 1}-t\left(G_{2}-G_{1}\right) \leq 0\end{array}\right.$, the optimal decision under centralized decision is:

$\left\{\begin{array}{l}p_{1}^{*}=\frac{c_{f 1}+t G_{1}}{2} \\ p_{2}{ }^{*}=\frac{c_{f 2}+t G_{2}}{2}\end{array}\right.$

The revenue of the whole supply chain is :

$\pi_{s c}^{*}=\frac{t G_{1}-c_{f 1}}{2} \cdot \frac{G_{1} c_{f 2}-G_{2} c_{f 1}}{2 t G_{1}\left(G_{2}-G_{1}\right)}+\frac{t G_{2}-c_{f 2}}{2} \cdot \frac{t\left(G_{2}-G_{1}\right)+c_{f 1}-c_{f 2}}{2 t\left(G_{2}-G_{1}\right)}$

When we solve the model (7),we found that compared to the supermarket sells only ordinary agricultural products or green agricultural products, when the supermarket carries out different management, the entire supply chain can gain more revenue. So it is necessary for the supermarket to carry out different management. Property 2.

When $\left\{\begin{array}{c}G_{2} c_{f 1}-G_{1} c_{f 2} \leq 0 \\ c_{f 2}-c_{f 1}-t\left(G_{2}-G_{1}\right) \leq 0\end{array}, \quad\right.$ in a centralized decision

(1) The sell price of ordinary agricultural products is only related to the production cost and green digree of ordinary agricultural products. And when production cost and green digree of ordinary agricultural products rises, sale price of ordinary agricultural products will rise;

(2) The sell price of green agricultural products is only related to the production cost and green digree of green agricultural products. And when production cost and green digree of green agricultural products rises, sale price of green agricultural products will rise

\section{Decentralized decision model}

We study the decentralized decision model based on Stackelberg game, and the farmer is the leader of the game, the supermarket is the follower.We assume the supermarket has two kinds of purchase model, one is choosing one farmer to purchase ordinary agricultural products and green agricultural products at the same time ,another is choosing two farmers to purchase ordinary agricultural products and green agricultural products separately. 


\subsection{Supermarket choosing one farmer}

In this section,we assuse that the supermarket chooses one farmer .

The game model is:

$$
\begin{gathered}
\max _{f}\left(w_{f 1}, w_{f 2}\right)=\max \left\{\left(w_{f 1}-c_{f 1}+c_{s} g_{1}\right) \frac{G_{1} p_{2}-G_{2} p_{1}}{t G_{1}\left(G_{2}-G_{1}\right)}\right. \\
\left.+\left(w_{f 2}-c_{f 2}+c_{s} g_{2}\right) \frac{1}{t}\left(t-\frac{p_{2}-p_{1}}{G_{2}-G_{1}}\right)\right\} \\
\text { s.t. } \max \pi_{s}\left(p_{1}, p_{2}\right)=\max \left\{\left(p_{1}-w_{f 1}-c_{s} g_{1}\right) \frac{G_{1} p_{2}-G_{2} p_{1}}{t G_{1}\left(G_{2}-G_{1}\right)}\right. \\
\left.+\left(p_{2}-w_{f 2}-c_{s} g_{2}\right) \frac{1}{t}\left(t-\frac{p_{2}-p_{1}}{G_{2}-G_{1}}\right)\right\} \\
p_{1} G_{2}-p_{2} G_{1} \leq 0 \\
p_{2}-p_{1}-t\left(G_{2}-G_{1}\right) \leq 0
\end{gathered}
$$

The model (10) was solved by inverse method, First, solve the planning problem:

$$
\begin{aligned}
\max \pi_{s}\left(p_{1}, p_{2}\right) & =\max \left\{\left(p_{1}-w_{f 1}-c_{s} g_{1}\right) \frac{G_{1} p_{2}-G_{2} p_{1}}{t G_{1}\left(G_{2}-G_{1}\right)}\right. \\
& \left.+\left(p_{2}-w_{f 2}-c_{s} g_{2}\right) \frac{1}{t}\left(t-\frac{p_{2}-p_{1}}{G_{2}-G_{1}}\right)\right\} \\
\text { s.t. } & p_{1} G_{2}-p_{2} G_{1} \leq 0 \\
& p_{2}-p_{1}-t\left(G_{2}-G_{1}\right) \leq 0
\end{aligned}
$$

So for the whole model (11), the best wholesale price

is: $\left\{\begin{array}{l}w_{f 1}^{* *}=\frac{c_{f 1}+t G_{1}-2 c_{s} g_{1}}{2} \\ w_{f 2}{ }^{* *}=\frac{c_{f 2}+t G_{2}-2 c_{s} g_{2}}{2}\end{array}\right.$

Then we plug (12) into $\pi_{f}\left(w_{f 1}, w_{f 2}\right)$, and we solve the model :

$$
\begin{gathered}
\max \pi_{f}\left(w_{f 1}^{* *}, w_{f 2}^{* *}\right)=\max \left\{\left(w_{f 1}^{* *}-c_{f 1}+c_{s} g_{1}\right) \frac{G_{1} p_{2}-G_{2} p_{1}}{t G_{1}\left(G_{2}-G_{1}\right)}\right. \text { ? } \\
\left.+\left(w_{f 2}^{* *}-c_{f 2}+c_{s} g_{2}\right) \frac{1}{t}\left(t-\frac{p_{2}-p_{1}}{G_{2}-G_{1}}\right)\right\} \\
\text { s.t. } \quad p_{1} G_{2}-p_{2} G_{1} \leq 0 \\
\quad p_{2}-p_{1}-t\left(G_{2}-G_{1}\right) \leq 0
\end{gathered}
$$

We solve the model(13), and the optimal sale price is :

$\left\{\begin{array}{l}p_{1}^{* *}=\frac{c_{f 1}+3 t G_{1}}{4} \\ p_{2}^{* *}=\frac{c_{f 2}+3 t G_{2}}{4}\end{array}\right.$

Property 3. In decentralized decision model, when supermarket chooses one farmers ,compared to supermarket sells only ordinary or green agricultural products, supermarket will choose to carry out different management .

Under decentralized decision making, when the supermarket selects one farmer, the profits of the supermarket is:

$\pi_{s}^{* *}=\frac{t G_{1}-c_{f 1}}{4} \cdot \frac{G_{1} c_{f 2}-G_{2} c_{f 1}}{4 t G_{1}\left(G_{2}-G_{1}\right)}+\frac{t G_{2}-c_{f 2}}{4} \cdot \frac{t\left(G_{2}-G_{1}\right)-c_{f 2}+c_{f 1}}{4 t\left(G_{2}-G_{1}\right)}$
The profits of the whole supply chain is:

$\pi_{s c}^{* *}=\frac{3\left(t G_{1}-c_{f 1}\right)}{4} \cdot \frac{G_{1} c_{f 2}-G_{2} c_{f 1}}{4 t G_{1}\left(G_{2}-G_{1}\right)}+\frac{3\left(t G_{2}-c_{f 2}\right)}{4} \cdot \frac{t\left(G_{2}-G_{1}\right)+c_{f 1}-c_{f 2}}{4 t\left(G_{2}-G_{1}\right)}$

Property 4. Under the decentralized decision, when $\left\{\begin{array}{c}G_{2} c_{f 1}-G_{1} c_{f 2} \leq 0 \\ c_{f 2}-c_{f 1}-t\left(G_{2}-G_{1}\right) \leq 0\end{array}\right.$, and the supermarket selects one farmer, it is compared with the centralized decision:

(1) The sell price of ordinary agricultural products and green agricultural products under decentralized decision making is higher than that under centralized decision;

(2) The profits of the whole supply chain under centralized decision is greater than under decentralized decision.

\subsection{Supermarkets select two farmers}

In this section,we assuse that the supermarket chooses two farmers. One farmer plants ordinary agricultural products, another plants green agricultural products . The information is completely symmetrical,and they know each other's information

The game model is:

$$
\begin{gathered}
\max _{f 1}\left(w_{f 1}\right)=\max \left\{\left(w_{f 1}-c_{f 1}+c_{s} g_{1}\right) \frac{G_{1} p_{2}-G_{2} p_{1}}{t G_{1}\left(G_{2}-G_{1}\right)}\right\} \\
\max _{f 2}\left(w_{f 2}\right)=\max \left\{\left(w_{f 2}-c_{f 2}+c_{s} g_{2}\right) \frac{1}{t}\left(t-\frac{p_{2}-p_{1}}{G_{2}-G_{1}}\right)\right\} \\
\text { s.t. } \max \pi_{s}\left(p_{1}, p_{2}\right)=\max \left\{\left(p_{1}-w_{f 1}-c_{s} g_{1}\right) \frac{G_{1} p_{2}-G_{2} p_{1}}{t G_{1}\left(G_{2}-G_{1}\right)}\right. \\
\left.+\left(p_{2}-w_{f 2}-c_{s} g_{2}\right) \frac{1}{t}\left(t-\frac{p_{2}-p_{1}}{G_{2}-G_{1}}\right)\right\} \\
p_{1} G_{2}-p_{2} G_{1} \leq 0 \\
p_{2}-p_{1}-t\left(G_{2}-G_{1}\right) \leq 0
\end{gathered}
$$

Similarly,we solve model (17) by inverse method.

Property 5 Under the decentralized decision, when $\left\{\begin{array}{c}G_{2} c_{f 1}-G_{1} c_{f 2} \leq 0 \\ c_{f 2}-c_{f 1}-t\left(G_{2}-G_{1}\right) \leq 0\end{array}\right.$, and the supermarket selects two farmers, the optimal decision is:

$$
\left\{\begin{array}{l}
p_{1}^{* * *}=\frac{2 G_{2} c_{f 1}+G_{1} c_{f 2}+t G_{1}\left(5 G_{2}-2 G_{1}\right)}{2\left(4 G_{2}-G_{1}\right)} \\
p_{2}^{* * *}=\frac{G_{2} c_{f 1}+2 G_{2} c_{f 2}+3 t G_{2}\left(2 G_{2}-G_{1}\right)}{2\left(4 G_{2}-G_{1}\right)} \\
w_{f 1}^{* * *}=\frac{2 G_{2} c_{f 1}+G_{1} c_{f 2}+t G_{1}\left(G_{2}-G_{1}\right)-c_{s} g_{1}\left(4 G_{2}-G_{1}\right)}{4 G_{2}-G_{1}} \\
w_{f 2}^{* * *}=\frac{G_{2} c_{f 1}+2 G_{2} c_{f 2}+2 t G_{2}\left(G_{2}-G_{1}\right)-c_{s} g_{2}\left(4 G_{2}-G_{1}\right)}{4 G_{2}-G_{1}}
\end{array}\right.
$$

The profits of supermarket is:

$$
\begin{aligned}
\pi_{s}^{* *}= & \frac{3 t G_{1} G_{2}-2 G_{2} c_{f 1}-G_{1} c_{f 2}}{2\left(4 G_{2}-G_{1}\right)} \cdot \frac{G_{2}\left(G_{1}-2 G_{2}\right) c_{f_{1}}+G_{1} G_{2} c_{f 2}+t G_{1} G_{2}\left(G_{2}-G_{1}\right)}{2 t G_{1}\left(G_{2}-G_{1}\right)\left(4 G_{2}-G_{1}\right)} \\
& +\frac{t G_{2}\left(2 G_{2}+G_{1}\right)-G_{2} c_{f 1}-2 G_{2} c_{f 2}}{2\left(4 G_{2}-G_{1}\right)} \cdot \frac{G_{2} c_{f 1}-\left(2 G_{2}-G_{1}\right) c_{f 2}+2 t G_{2}\left(G_{2}-G_{1}\right)}{2 t\left(G_{2}-G_{1}\right)\left(4 G_{2}-G_{1}\right)}
\end{aligned}
$$


And the supermarket's profits which chooses two farmers is greater than the that which chooses one farmer.

From the property 5, it can know that the supermarket's profits which chooses two farmers is greater than the that which chooses one farmer .Supermarket chooses two farmers, and let the two farmers compete, then the supermarkets can get greater profits. Moreover, the output of the agricultural products is greatly influenced by the weather and so on. The supermarket chooses two farmers to order ordinary agricultural products and green agricultural products respectively, and will also reduce the risk of the agricultural products supply influenced by the weather and so on.

\subsection{Supply chain coordination}

This part proposes a "wholesale price + ordering subsidy" coordination mechanism. In order to increase the order quantity of the supermarket, also in order to make supermarket and farmers become a closer interest community, at the end of the deal, farmers will take part of their own income to give certain subsidies to supermarket. It is assumed that farmers' ordering subsidies to supermarkets are: $\varphi_{1} w_{f 1} Q_{1}+\varphi_{2} w_{f 2} Q_{2} \cdot \varphi_{1}$ is the proportion of the farmers' ordering subsidy for the ordinary agricultural products and $\varphi_{2}$ is that of green agricultural products.

Under the "wholesale price + ordering subsidy" contract, the problem of supermarket planning is :

$$
\begin{aligned}
\max \pi_{s}\left(p_{1}, p_{2}\right)=\max \left\{\left(p_{1}-w_{f 1}-c_{s} g_{2}\right)\right. & \frac{G_{1} p_{2}-G_{2} p_{1}}{G_{1}\left(G_{2}-G_{1}\right)}+\varphi_{1} w_{f 1} \frac{G_{1} p_{2}-G_{2} p_{1}}{t G_{1}\left(G_{2}-G_{1}\right)} \\
& \left.\quad+\left(p_{2}-w_{f 2}-c_{s} g_{2}\right) \frac{1}{t}\left(t-\frac{p_{2}-p_{1}}{G_{2}-G_{1}}\right)+\varphi_{2} w_{f 2} \frac{1}{t}\left(t-\frac{p_{2}-p_{1}}{G_{2}-G_{1}}\right)\right\} \\
\text { s.t. } \quad & G_{2} p_{1}-G_{1} p_{2} \leq 0 \\
& p_{2}-p_{1}-t\left(G_{2}-G_{1}\right) \leq 0
\end{aligned}
$$

Property 7. When $\left\{\begin{array}{c}G_{2} c_{f 1}-G_{1} c_{f 2} \leq 0 \\ c_{f 2}-c_{f 1}-t\left(G_{2}-G_{1}\right) \leq 0\end{array}\right.$, in the "wholesale price + purchase subsidy" contract, the optimal decision is:

$$
\left\{\begin{array}{l}
p_{1}^{* * *}=\frac{\left(1-\varphi_{1}\right) w_{f 1}+t G_{1}+c_{s} g_{1}}{2} \\
p_{2}^{* * *}=\frac{\left(1-\varphi_{2}\right) w_{f 2}+t G_{2}+c_{s} g_{2}}{2}
\end{array}\right.
$$

And the contract parameter $\left(w_{f 1}, \varphi_{1}, w_{f 2}, \varphi_{2}\right)$ satisfies the following relationship, the "wholesale price + subscription subsidy" contract can coordinate the whole supply chain:

$$
\left\{\begin{array}{l}
w_{f 1}=\frac{c_{f 1}-c_{s} g_{1}}{1-\varphi_{1}} \\
w_{f 2}=\frac{c_{f 2}-c_{s} g_{2}}{1-\varphi_{2}}
\end{array}\right.
$$

\begin{tabular}{|c|c|c|c|}
\hline & \multirow{2}{*}{$\begin{array}{c}\text { Centralized } \\
\text { decision- } \\
\text { making }\end{array}$} & \multicolumn{2}{|c|}{$\begin{array}{l}\text { decentralized decision- } \\
\text { making }\end{array}$} \\
\hline & & One farmer & $\begin{array}{l}\text { Two } \\
\text { farmers }\end{array}$ \\
\hline$p_{1}$ & 3 & $7 / 2$ & $45 / 14$ \\
\hline$p_{2}$ & $13 / 2$ & $29 / 4$ & $48 / 7$ \\
\hline$\pi_{s}$ & $*$ & $5 / 64$ & $73 / 392$ \\
\hline$\pi_{s c}$ & $5 / 16$ & $15 / 64$ & $116 / 392$ \\
\hline
\end{tabular}

\section{Numerical example}

Based on assumption $\left\{\begin{array}{c}G_{2} c_{f 1}-G_{1} c_{f 2} \leq 0 \\ c_{f 2}-c_{f 1}-t\left(G_{2}-G_{1}\right) \leq 0\end{array}\right.$

let $\quad \mathrm{k}=1, \mathrm{a}=3, \mathrm{~b}=1, G_{1}=0.4\left(g_{1}=0.69\right)$

$G_{2}=0.8\left(g_{2}=2.48\right), c_{f 1}=2, c_{f 2}=5, c_{s}=1, t=10$

Table 1.

From table 1, we can get the following conclusions. The profits of the entire supply chain under centralized decision are greater than that under decentralized decision .So supermarket and farmers can choose cooperate by coordination mechanism (this paper is "wholesale + order subsidy coordination mechanism") to get more profits. Under centralized decision making, the selling prices of ordinary agricultural products and green agricultural products are lower than that under decentralized decision making. Therefore, when supermarket cooperate with farmers, supermarkets 、 farmers and consumers can benefit from it.

Under decentralized decision, the supermarket's profit which chooses two farmers is greater than the that which chooses one farmer .Supermarket chooses two farmers, and let the two farmers compete, then the supermarkets can get greater profits.

In figure 2, the horizontal coordinate is the green degree $g_{1}$ of ordinary agricultural products, and the vertical coordinate is the selling price of agricultural products. $g_{2}=2.48, c_{f 1}=2, c_{f 2}=5, c_{s}=1, t=10$. Can be seen from the figure 2 , when ordinary agricultural products' green degree increases, the ordinary agricultural products sale price increase, but the green agricultural products sale prices unchanged.

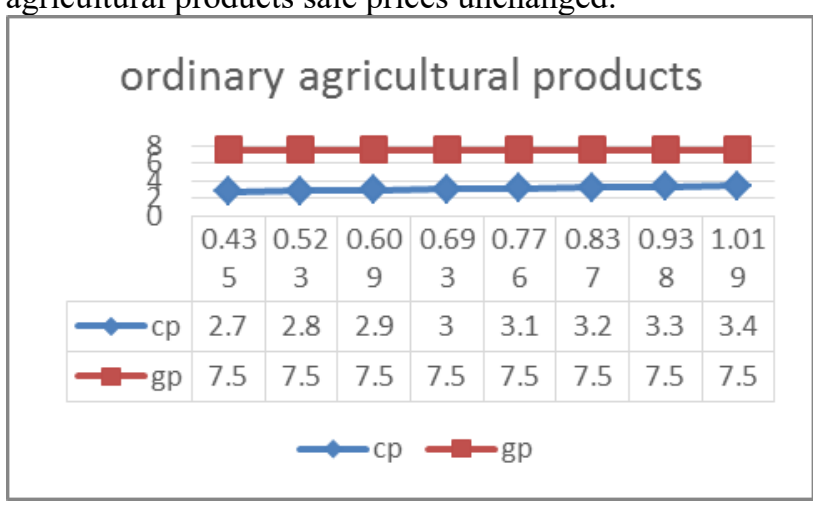

( $\mathrm{cp}$ :common agricultural products price ;gp :green agricultural products price)

FIG. 2 the trend of the sales price of ordinary agricultural products with the change of green degree $g_{1}$ 


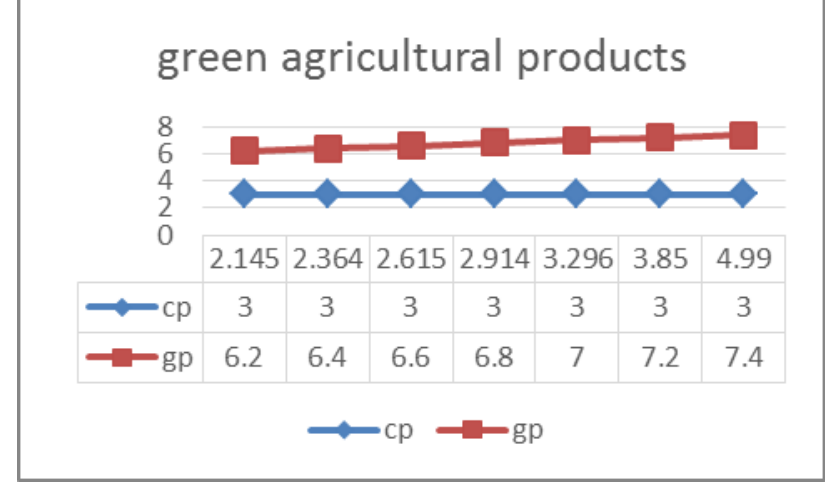

( $\mathrm{cp}$ :common agricultural products price ;gp :green agricultural products price)

FIG. 3 the trend of the sales price of agricultural products with the green degree of green agricultural $g_{2}$.

In figure 3, the horizontal coordinate is the green degree $g_{2}$ of green agricultural products, and the vertical coordinate is the sell price of agricultural products. In figure $3, g_{1}=0.69, c_{f 1}=2, c_{f 2}=5, c_{s}=1, t=10$. As can be seen from the figure 3 , when the green degree of green agricultural products increases, the sale price of green agricultural products increases, but the ordinary agricultural products sales prices unchanged

Table 2 the profitability of supply chain under centralized decision-making.

\begin{tabular}{|l|c|c|c|}
\hline & $\begin{array}{l}\text { Sell only } \\
\text { green } \\
\text { products }\end{array}$ & $\begin{array}{l}\text { Sell only } \\
\text { ordinary } \\
\text { products }\end{array}$ & $\begin{array}{l}\text { different } \\
\text { operation }\end{array}$ \\
\hline $\begin{array}{l}g_{1}=0.693, \\
g_{2}=2.48\end{array}$ & $9 / 32$ & $1 / 4$ & $5 / 16$ \\
\hline $\begin{array}{l}g_{1}=0.898, \\
g_{2}=3.296\end{array}$ & $4 / 9$ & $25 / 72$ & $13 / 27$ \\
\hline
\end{tabular}

By comparing, table 2 shows that when supermarket carry out different management, the profits of the entire supply chain is the highest .

Table 3 farmer's profit for supermarket choosing one farmer under decentralized decision

\begin{tabular}{|l|c|c|c|}
\hline & $\begin{array}{l}\text { Sell only } \\
\text { green } \\
\text { products }\end{array}$ & $\begin{array}{l}\text { Sell only } \\
\text { ordinary } \\
\text { products }\end{array}$ & $\begin{array}{l}\text { different } \\
\text { management }\end{array}$ \\
\hline $\begin{array}{l}g_{1}=0.693, \\
g_{2}=2.48\end{array}$ & $9 / 64$ & $1 / 8$ & $5 / 32$ \\
\hline $\begin{array}{l}g_{1}=0.898, \\
g_{2}=3.296\end{array}$ & $2 / 9$ & $25 / 144$ & $13 / 54$ \\
\hline
\end{tabular}

By comparing, table 5 shows that under decentralized decision, when supermarket that choose one farmer carries out different management, the profit of farmer is the highest .Because farmer is the leaders of the Stackelberg game, farmers will make appropriate wholesale prices of agricultural products to make supermarket carries out different management.

To sum up from table 2 and table 3 , supermarket carrying out different management is necessary.

\section{Conclusion}

This paper studies the supply chain of green agricultural products with "agricultural super docking" mode based on the different management. We built a consumer utility function which relate to green degree and sale price. Consumers choose their own purchase behavior based on the consumer utility function.

We get that supermarket carrying out different management is necessary. Based on the optimal solution of concentrated model and decentralized model, sell price of ordinary agricultural products and green agricultural products is only related to themselves.Compared to supermarket choosing one farmer,supermarket can get more profits when it choose two farmers under decentralized decision. Finally, we coordinate the whole supply chain with "wholesale price + ordering subsidy" coordination mechanism .

This paper consider the green degree of agricultural products as a constant, then the following research can consider the green degree as decision variables, to find the optimal green degree which make the supermarket to get maximum. Agricultural production is closely related to some factors such as weather, so there is a certain risk. In the following research, we can consider the riskin order to take better decisions.

\section{References}

1. Reardon T, Timmer C P, Barrett C B, et al. The Rise of Supermarkets in Africa, Asia, and Latin America[J]. American Journal of Agricultural Economics, 2003, 85(5):1140-1146.

2. Reardon T, Swinnen J F M. Agrifood Sector Liberalisation and the Rise of Supermarkets in Former State-controlled Economies: A Comparative Overview[M]// Development Policy Review. 2004:515-523.

3. Jiang Zeng-wei, Agricultural super docking: A good form of regurgitating agriculture $[\mathrm{J}]$, Agricultural economy, 2009(12):38-40

4. Hu Ding-huan, Yang Wei-min, "Agricultural super docking": Meaning and challenge [J]. Rural management and administration, 2010(4):17-19.

5. Li B, Zhu M, Jiang Y, et al. Pricing policies of a competitive dual-channel green supply chain[J]. Journal of Cleaner Production, 2016, 112(20):20292042.

6. Liu Z, Anderson T D, Cruz J M. Consumer environmental awareness and competition in twostage supply chains[J]. European Journal of Operational Research, 2012, 218(3):602-613.

7. Fu Li-fang, Deng Hua-ling, Wei Wei, Xu Shi-yang, Analysis of Influencing Factors and Consumption Behavior of Green Agricultural Products Based on Probit Model [J]. Ecological Economy, 2014.07, 30(7):60-64. 